\title{
Content Analysis of Health-Based Iranian Systems and Apps on Covid-19
}

\section{ART ICLE INF O}

\section{Article Type}

Descriptive Study

\section{Authors}

Abdolkarimi Sh. ${ }^{1} B S C$, Mousavi B. ${ }^{* 2} M D, M P H$, Montaseri A. ${ }^{3} B S C$

\section{A B S T R A C T}

Aims E-health services play an important role in controlling the epidemic, implementing quarantine and responding to current and future health needs. The aim of the study was to evaluate the quality and content of Persian-centric covid -19 health systems and - applications

Instrument \& Methods In this descriptive study, the feedback and information of Iranian health-oriented applications and systems (screening, prevention and treatment) related to Covid-19 and having direct and indirect interaction with users in December 2020 were examined. Keyword (s): system, site, software, application, app, installation, sars-cov-2, covid-19, coronavirus, covid-19, coronavirus, self-assessment, health, care, consulting, screening, prevention, follow, disease, diagnosis, treatment, emergency, instructions, training, online, online and testing were searched on the sites of Google, Yahoo and Bing and the markets of Bazaar Cafe, Miket, Charkhooneh, Anardoni, Apple App, Sibcheh. Then the software and systems were reviewed and the items related to Covid-19 were evaluated based on the MARS scale.

Findings Iranian health-oriented apps/systems included 8 applications, 4 systems and 4 mobile application systems. The total number of installed applications in the country was 941173 and "Mask" had the highest installation with 75\% (n=700000). The acceptance rate/ use of Covid-19 screening-treatment systems and applications was $2.2 \%$ of the population with smartphones in the country. Based on the ranking scale of the smartphone application, the highest average was in the dimension of information (3.2) and the lowest was in the individual perception of the quality of the application (2) and interaction (2.3) (total average 2.6). The 4030, Clinic, Mask, and Corona-115 apps scored the most points with 3.6, 3.5, 3.3, and 3.1 out of 5 , respectively.

Conclusion This study suggests that most COVID-related apps meet acceptable criteria for content, or functionality, and poor criteria for quality, esthetic and interesting features.

Keywords Coronavirus; Mobile Health; Telemedicine; Covid-19
${ }^{1}$ Janbazan Medical and Engineering Research Center (JMERC), Tehran, Iran

${ }^{2}$ Prevention Department, Janbazan Medical and Engineering Research Center (JMERC), Tehran, Iran

${ }^{3}$ Asre Danesh Afzar Company, Tehran, Iran

\section{*Correspondence}

Address: Janbazan Medical and Engineering Research Center (JMERC), Tehran, Iran. Postal Code: 1985946563

Phone: +98 (21) 22416699

Fax: +98 (21) 22412114

mousavi.b@gmail.com

\section{Article History}

Received: October 28, 2020

Accepted: November 30, 2020

ePublished: March 07, 2021

\section{I T A T I O N L I N K S}

[1] Estimating the unreported ... [2] A precision medicine ... [3] Origin and evolution of pathogenic ... [4] Coronavirus: Scientometrics ... [5] The rate of underascertainment ... [6] SARS-CoV, MERS-CoV and now ... [7] Publisher City Unknown ... [8] Community transmission of ... [9] Clinical features of patients ... [10] Digital health strategies to fight ... [11] Use of mobile phone apps for ... [12] Content analysis of Iranian ... [13] Social media for rapid knowledge ... [14] Ethics of instantaneous ... [15] Bates. design and testing of ... [16] The effectiveness of self-management ... [17] Trust but verify-five approaches ... [18] A review and content analysis ... [19] Design and evaluation of ... [20] How will countrybased ... [21] Responding to community ... [22] COVID-19 contact tracing and data ... [23] New York: Bankmycell; 2020 ... [24] Publisher City Unknown: Canada ... [25] The role of telehealth in reducing ... [26] In coronavirus fight, China gives citizens ... [27] Applicability of mobile contact tracing ... [28] Features and functionalities of smartphone ... [29] A costminimization analysis ... [30] Mobile phone data for informing public ... [31] Global preparedness against COVID-19: We ... [32] Persistent digital divide in access ... [33] 15 smartphone apps for older adults to use ... [34] Fighting COVID-19 misinformation on social ... [35] Risk factors, and social media use during ... [36] Online mental health services in China ... [37] Digital mental health and COVID-19 ... [38] Digital health management during and ... [39] Health digital technology in COVID-19 ... 
Organization; WHO) ويروس اين خانواده محسوب شده و هشدار جدى براى تمام إمام

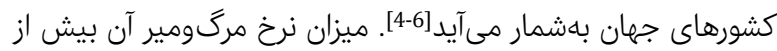

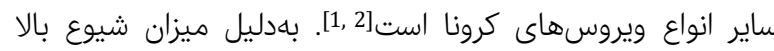

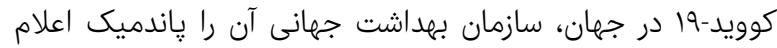

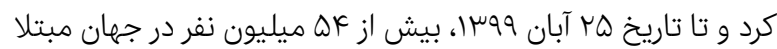
و بيش از يك ميليون مورد فوت ثبت شده است و سه كشيخ آنور آمريكا،

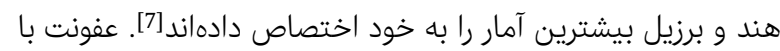
ويروس كرونا معمولاً بدون علامت يا در مرحله مقدماتى با با علايم غيراختصاصى همراه است [8, 9.

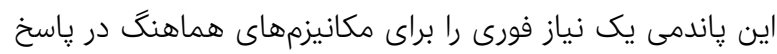

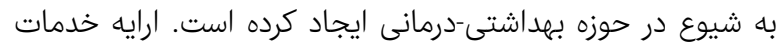

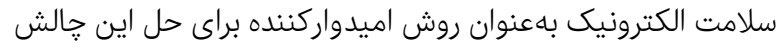

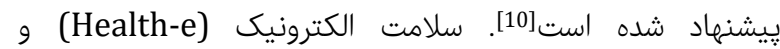

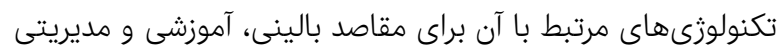

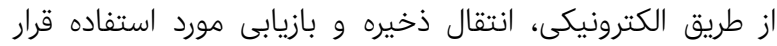

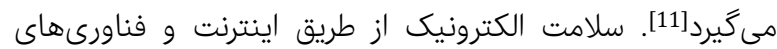

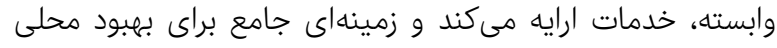

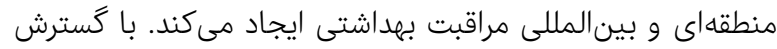

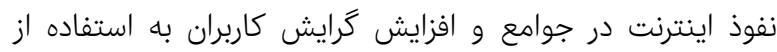
اينترنت، سلامت الكترونيك نيز دجار تحولى عظيم شده و و از كاربردى

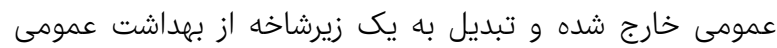

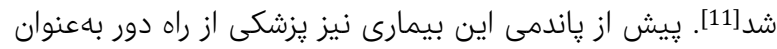

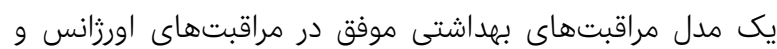
مراقبتهاى اوليه براى كاهش خطر عفونت استفاده شده بود [10].

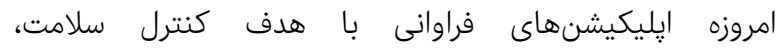

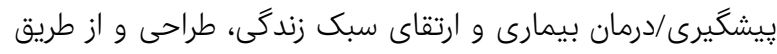

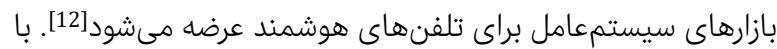

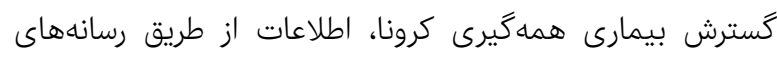

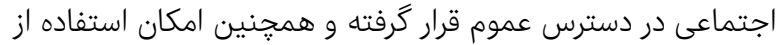

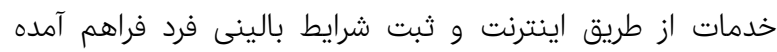

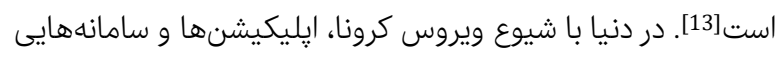

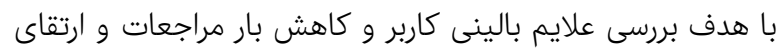

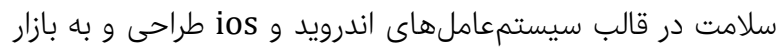

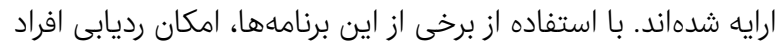

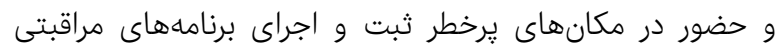

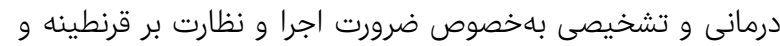

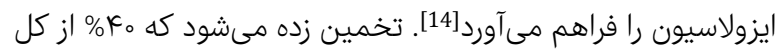

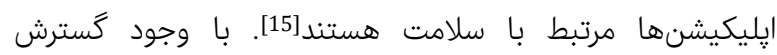
إيليكيشنهاى سلامت، نشان داده شده كه تعداد بسيار كمى بلى به

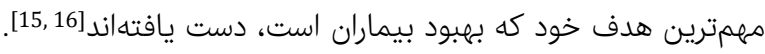

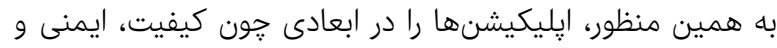

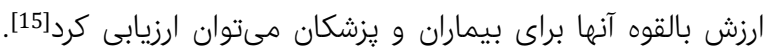

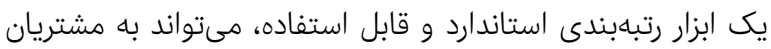

\section{تحليل محتواى سامانهها و آبهاى ايرانى}

سلامتمحور كوويد-19

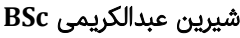

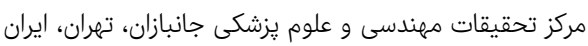

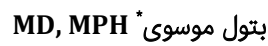

كَره بِيشَّيرى، مركز تحقيقات مهندسى و علوم بزشكى جانبازان، تهران، ايران

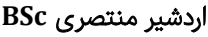

شركت عصر دانشافزار، تهران، ايران

جكيده

اهداف: خدمات سلامت الكترونيك نقش مهمى در كنترل همهيرى، اجراى

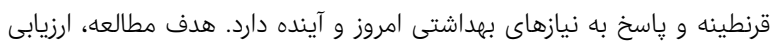

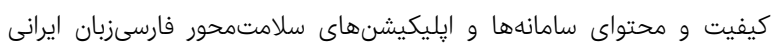

كوويد-19 بود.

ابزار و روشها: در اين يزوهش توصيفى بازخورد و اطلاعات إِليكيشنها و و وران

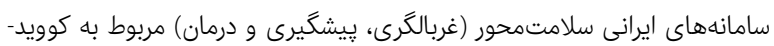

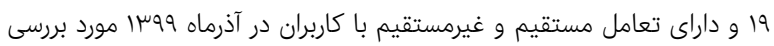

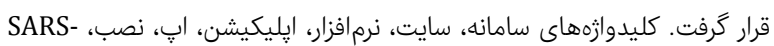
سلامت، CoV-2

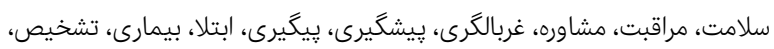

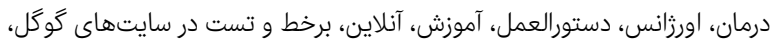

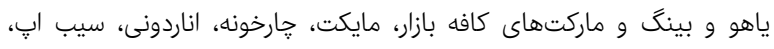

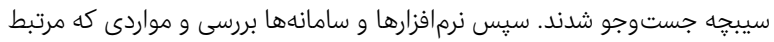
با كوويد-19 بودند، بر اساس مقياس MARS مورد ارزيابى قرار كرفتيند.

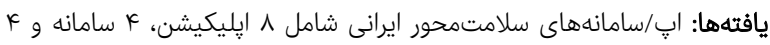

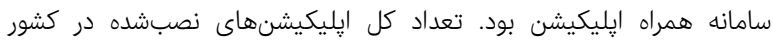

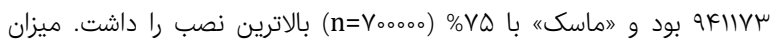

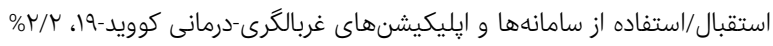

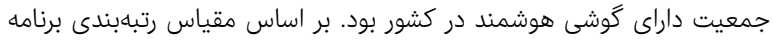

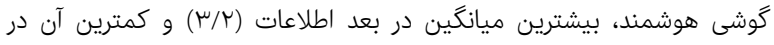

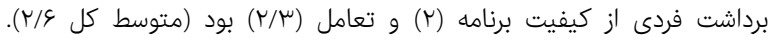

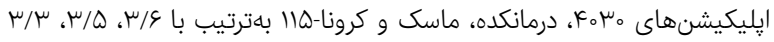

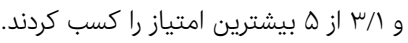
نتيجه

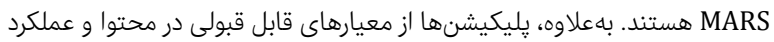

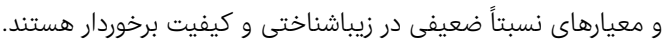

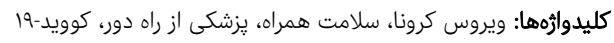

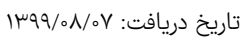

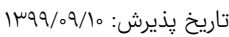

mousavi.b@gmail.com :نويسنده مسئول: بارئو

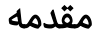

ويروس كرونا، عامل طيف وسيعى از بيمارىهاى ويروسى و عامل

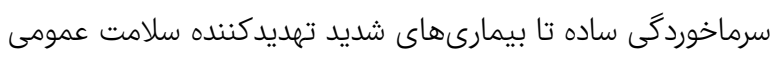

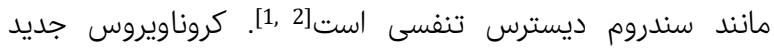

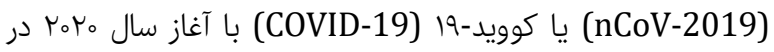

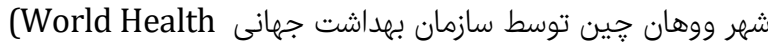




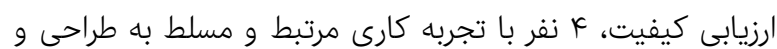

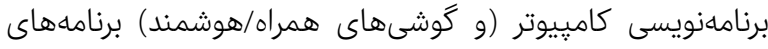

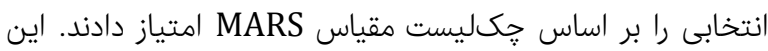

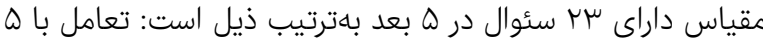

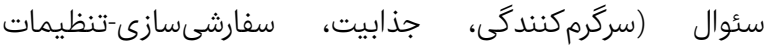

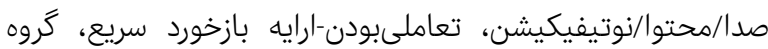

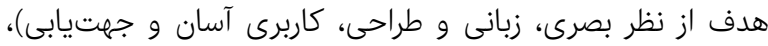

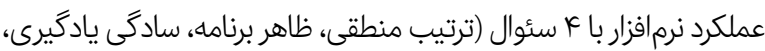

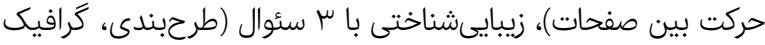

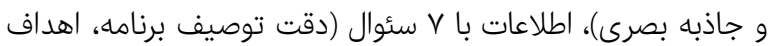

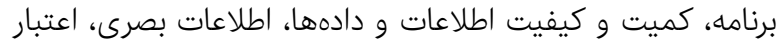

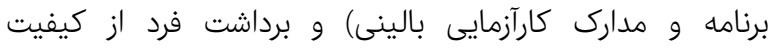

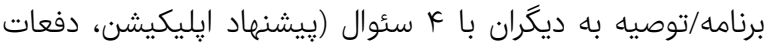

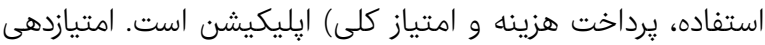

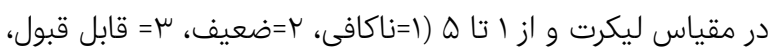

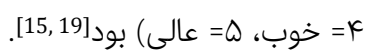
ويزَىهاى فنى و نرمافزارى إيليكيشنها و سامانهها به تفكيك

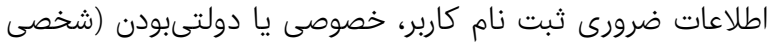

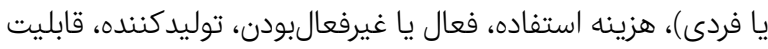

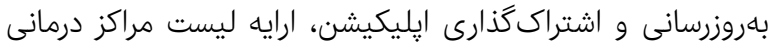

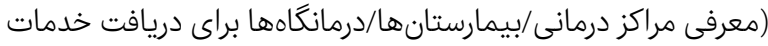

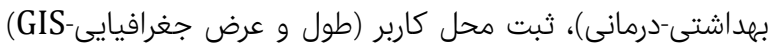

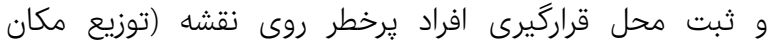

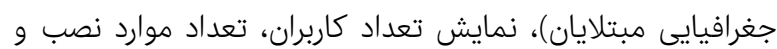

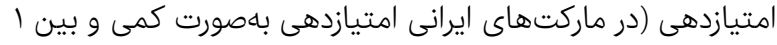

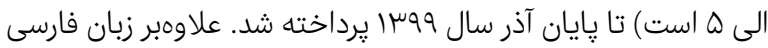

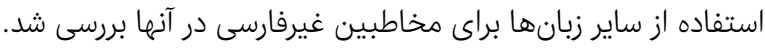

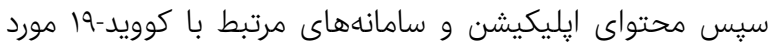

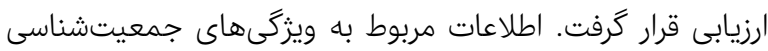

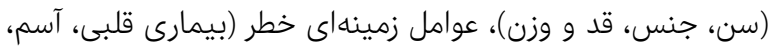

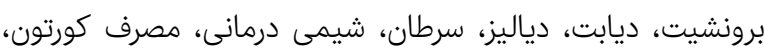

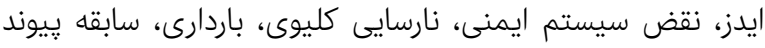

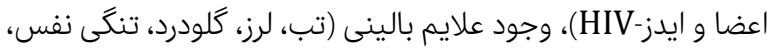

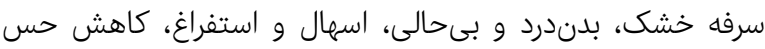

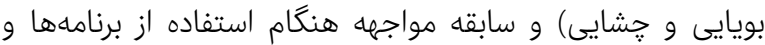

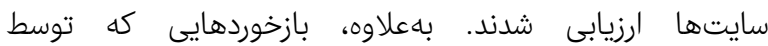

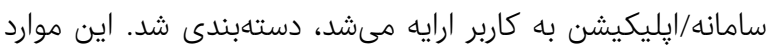

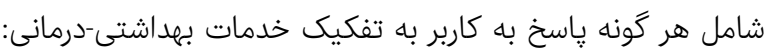

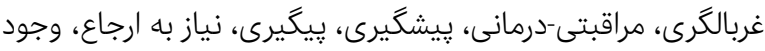

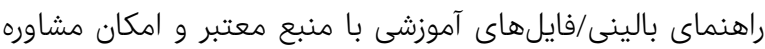

برخط با يزشك بود.

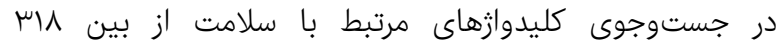

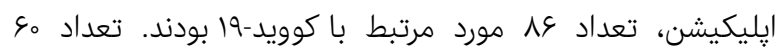

و يزشكان در تصميم گيرى آكاهانه در مورد استفاده از برنامه كمك

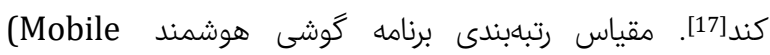
Application Rating Scale; MARS)

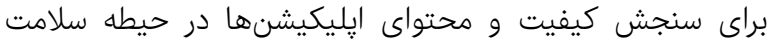

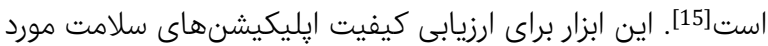

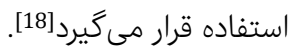

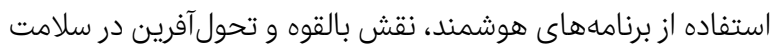

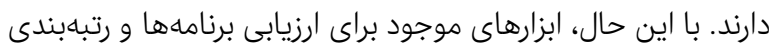

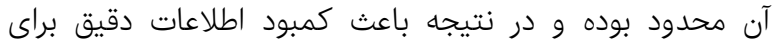

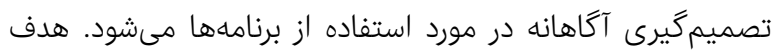

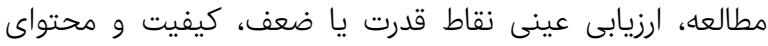
سامانهها و إِليكيشنهاى سلامتمحور فارسى-ايرانى كوويد-19 بود.

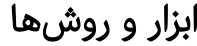

در اين يزوهش توصيفى بازخورد و اطلاعات إيليكيشنها و ورئاري

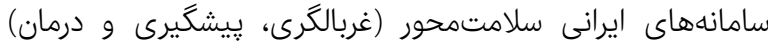

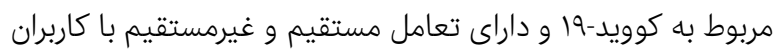

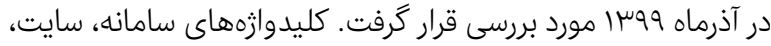

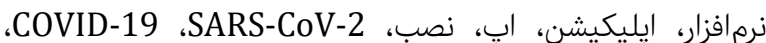
Coronavirus

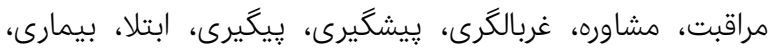

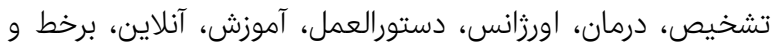

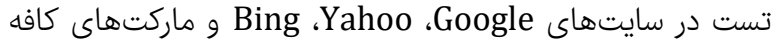

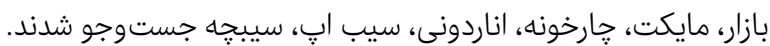

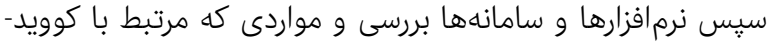

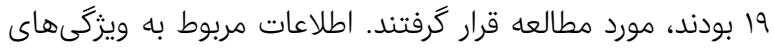
فنى و نرمافزارى، محتواى إيليكيشن/سامانهها و انواع بازخوردهايى كرايى

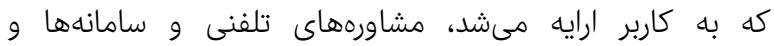
إيليكيشنهاى با تعامل غيرهستقيم مورد ارزيابى قرار گرفتند. تعامل

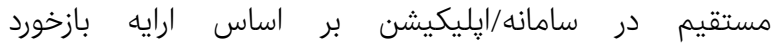
بهداشتى/درمانى به كاربر هنكام استفاده از نرمافزارها و شامل موارد الرايكان

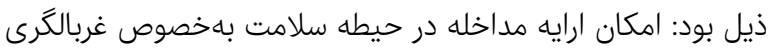

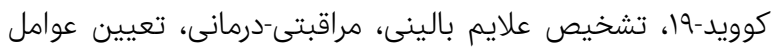

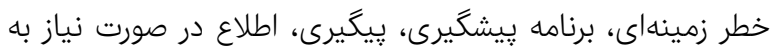

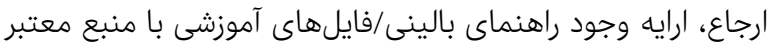

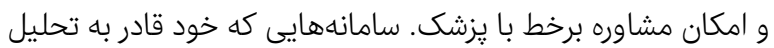
وضعيت كاربر و ارايه بازخورد نبودند و داراى لينكهايى برائ براى

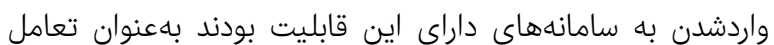
غيرمستقيم در نظر گرفته شدند. إيليكيشنها بر اساس مقياس MARS مورد ارزيابى قرار كرفتند شدند. مقياس MARS ابزارى ساده، عينى و قابل اعتماد در ارزيابى إسى

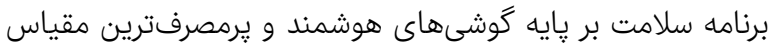

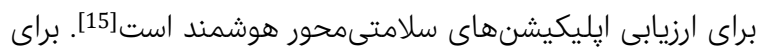




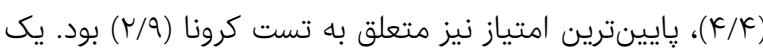

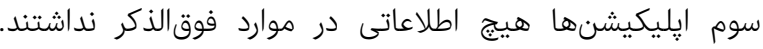

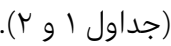

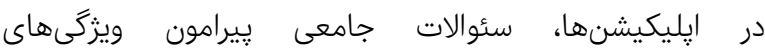
جمعيتشناسى، سابقه مواجهه احتمالى با بيمار مبتلا به كوويد-19

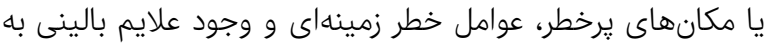

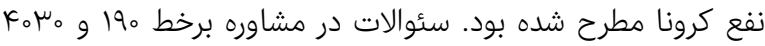

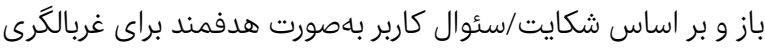
و درمان هدايت شده بود. سامانه خودارزيابى كرونا-اصفهان، داراى براي

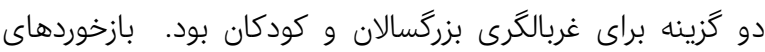

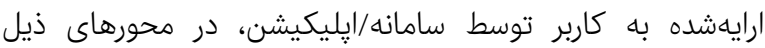

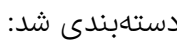

- تاييد مواجهه يا وجود عوامل خطر ابتلا، غربالكرى (تاييد وجود علايم بالينى احتمالى به نفع كرونا)؛ - نياز به ييكيرى مجدد در زمان توصيهشد؛

- نياز به مراجعه به مركز درمانى براى ارزيابى بيمارى كوويد-19 يا

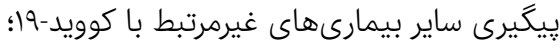
- امكان مشاوره برخط با يزشك؛

- راهنماى مراقبتى در صورت نياز به مراقبت در منزل؛ - ارايه راهنماى ييشگيرى در موارد نياز به قرنطينه-ايزولاسيون؛ - ارايه منبع معتبر براى راهنماها و دستورالعملهاى ارايهشه. اطلاعات مربوط به ويزگىهاى جمعيتشناسى، عوامل زمينهاى

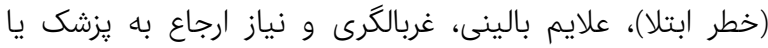

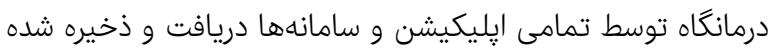
بود، اما اطلاعات مربوط به سابقه مواجهه در \& سامانه ارزيابى شده

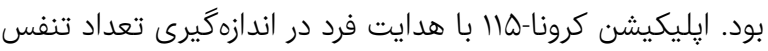
در دقيقه امكان تعيين درگيرى ريوى و نياز به ارجاع فورى به مراكز

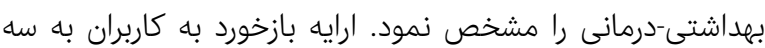

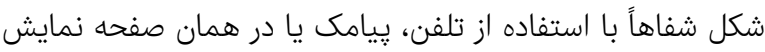

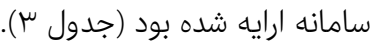

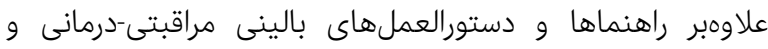
ييشگيرى (قرنطينه و ايزولاسيون)، يمفلتها، مقالات، مصاحبههاى

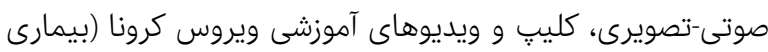

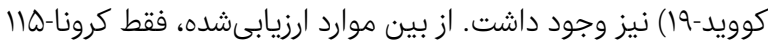
و تست آنلاين كرونا منبع معتبر براى بستههاى آموزشى، راهنماهيز آهاهيا

و دستورالعملهاى خود ارايه داده بودند (جدول سب).

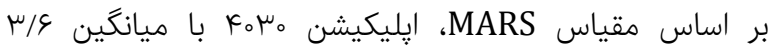
بيشترين امتياز را به خود اختصاص داد، درمانكده، ماسك ور كرونا-

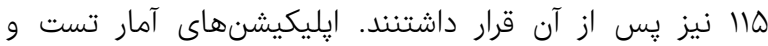
دانستنىهاى كرونا و تست كرونا كمترين امتياز را كسب كردند

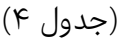

إِيكيشن بهصورت بازى يا صرفاً اطلاعرسانى و ارايه آمار تعداد

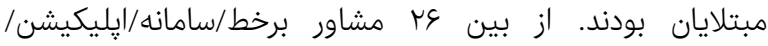

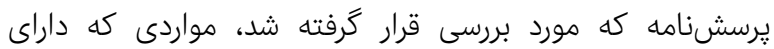

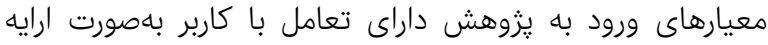

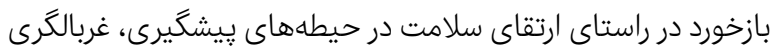

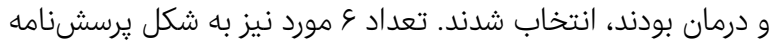

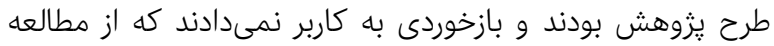
حذف شدند. از بين \& مشاور برخط مورد ارزيابى، ب مورد كه صرفاً بهصورت ييام صوتى و بدون بازخوردى بودند، از مطالعه حذف شدند.

يافتهها در كل \\ سامانه، إيليكيشن و مشاوره برخط (تلفن) در اين مطالعه

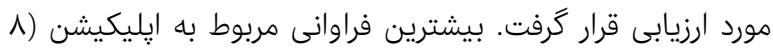

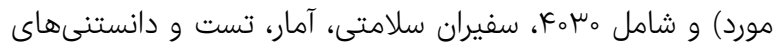

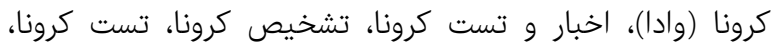

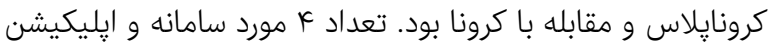
(درمانكده، ماسك، كرونا-ه||1، مقابله با كرونا)، K مورد فقط سامانه (خودارزيابى كرونا، خودارزيابى كرونا-وزارت بهداشت، تست آنلاين

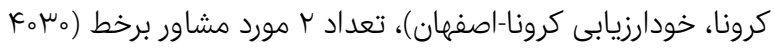

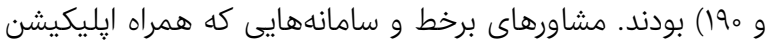

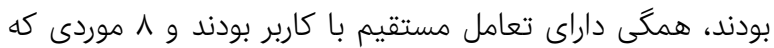
فقط إيليكيشن داشتند، تعامل غيرمستقيم با كاربر داشتند. سامانه

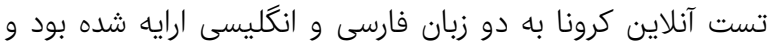
تنها سامانهاى بود كه امكان انتخاب زبان را به كاربر مى ديداد.

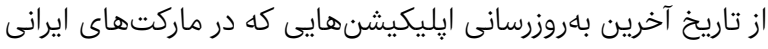

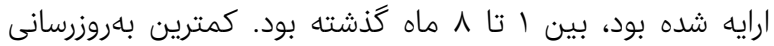

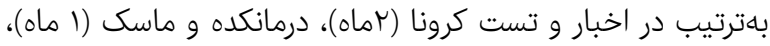
تست كرونا (عماه) و طولانىترين زمان نيز مربوط به به كرونايلاس،

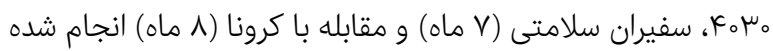
بود. سامانههاى ماسك، خودارزيابى كرونا، ايليكيشنهاى إن اخبار و و

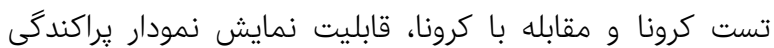
جمعيت مبتلايان به كرونا را روى نقشه بر اساس اطلاعات جغرافيايى فرد مبتلا را داشتند، ولى هيج يك امكان ثبت محل كاريت كاربر

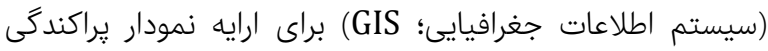
مبتلايان در اطراف كاربر را ارايه نداشتند. تمامى إيليكيشنها و سامانههاى مورد ارزيابى رايگان در درافر اختيار كاربران بودند و هض\% ايليكيشنها با حمايت وزارت بهداشت، درمان

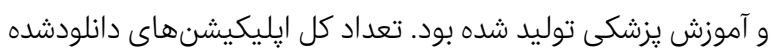

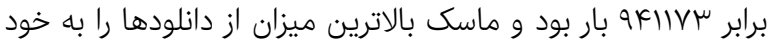
(\%VK/K)

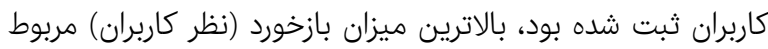

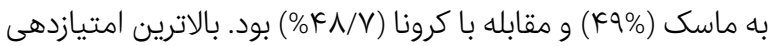

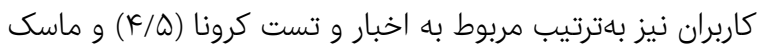


rYY تحليل محتواى سامانهها و آبهاى ايرانى سلامتمحور كوويد-19

جدول () ويزَگىهاى فنى إِليكيشنها و سامانهاى فعال غربالكَرى-درمانى كوويد-19 داراى امكان تعامل با كاربر

\begin{tabular}{|c|c|c|c|c|c|c|c|c|}
\hline 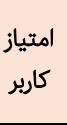 & كظرات & تصب تصداد & نحوه دسترسى & توليدكننده & مراكز درمانى & اشتراكگذارى & ن لحوه ثبت نام & إيليكيشن/سامانه \\
\hline$\mu / q$ & $\varepsilon_{0}$ & $\sum 7_{00}$ & 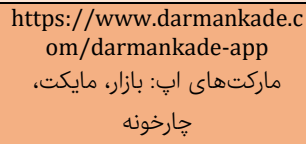 & خصوصى: سلامت هوشمند طاهران & $\checkmark$ & $x$ & 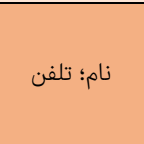 & $\begin{array}{c}\text { (ios \& android) } \\
\text { (ios) }\end{array}$ \\
\hline$\varepsilon / \mu q$ & $77 \vee \varepsilon$ & 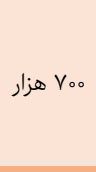 & 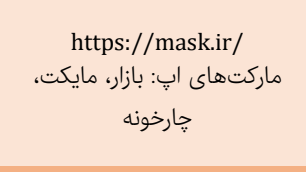 & 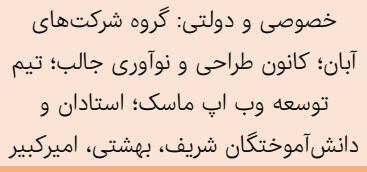 & $x$ & $\checkmark$ & تلفن & $\begin{array}{c}\text { ماسك } \\
\text { (android) }\end{array}$ \\
\hline - & - & rAVr & https://corona115.com & خصوصى: شركت نرمافزارى آلونى؛ & $\checkmark$ & $\checkmark$ & 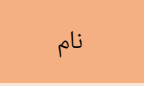 & $\begin{array}{c}\text { كرونا-S } \\
\text { (android) }\end{array}$ \\
\hline$\varepsilon / 1$ & $77 \varepsilon 1$ & مزار roo & $\begin{array}{l}\text { https://ac19.ir } \\
\text { ماركت اب: بازار }\end{array}$ & 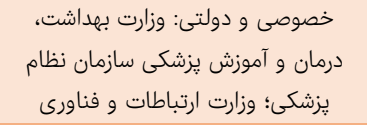 & $\checkmark$ & $x$ & ن ام؛ تلفن & $\begin{array}{l}\text { مقابله با كرونا } \\
\text { (android) }\end{array}$ \\
\hline - & - & - & $\begin{array}{l}\text { https://corona.research.ac.i } \\
\text { r/corona-screening }\end{array}$ & 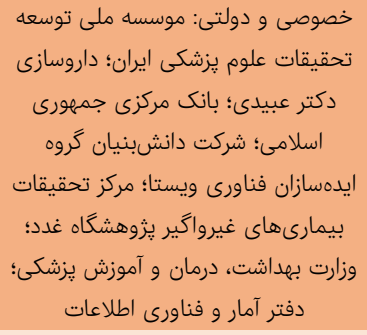 & $x$ & $\checkmark$ & بلدون ثبت نام & خودارزيابى كرونا \\
\hline- & - & - & $\begin{array}{c}\text { https://salamat.gov.ir/logi } \\
\text { n }\end{array}$ & دولتى: وزارت بهداشت، درمان و آموزش & $x$ & $x$ & كد ملى؛ ت تاريخ؛ & خودارزيابى كرونا-وزارت \\
\hline - & - & - & https://test.corona.ir/ & 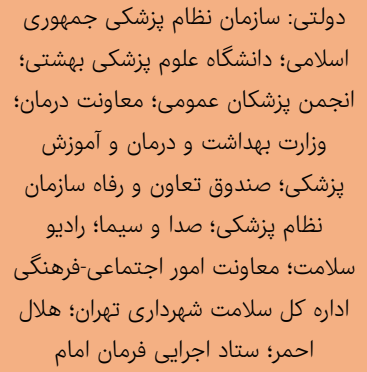 & $x$ & $x$ & بلدون ثبت نام & تست آنلاين كرونا \\
\hline - & - & - & $\begin{array}{l}\text { https://www.coronaisfaha } \\
\text { n.ir/checklist/26545 }\end{array}$ & دولتى: دانشعاه علوم يزشكى اصفهان & $\checkmark$ & $x$ & تلفن (اختيارى) & خودارزيابى كرونا-اصفهان \\
\hline - & - & - & شماره 019 با تلفن & دولتى: وزارت بهداشت، درمان و آموزش & $\checkmark$ & $x$ & ذخيره شماره & $(Y \times Y \varepsilon) 190$ \\
\hline - & - & - & شماره هـامع با تلفن & 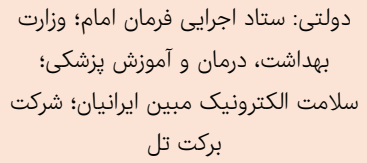 & $\checkmark$ & $x$ & ذخيره شماره & $\left(\gamma \times \varepsilon^{\prime}\right) \varepsilon_{0} \mu_{0}$ \\
\hline
\end{tabular}

جدول r) ويزّكىهاى فنى إيليكيشنهاى فعال غربالكرى-درمانى كوويد-19 داراى تعامل غيرهستقيم با كاربر

\begin{tabular}{|c|c|c|c|c|c|c|c|c|}
\hline ن نحوه ارايه بازخورد & امتياز كاربر & كعداد نظرات & تعداد نصب & نحوه دسترسى & 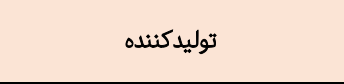 & مراكز درمانى & اشتراكگذارى & إليكيشن \\
\hline سامانه خودارزيابى & $x$ & $x$ & rooo & $\underline{\text { https://app.4030call.ir }}$ & 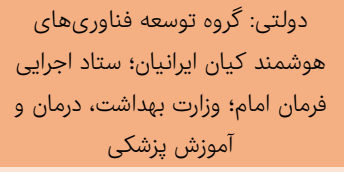 & $\checkmark$ & $x$ & $\varepsilon_{0} \psi_{0}$ \\
\hline 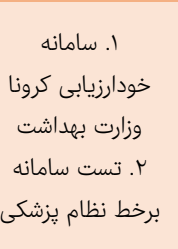 & $\mu / q$ & r.o & rmoo & 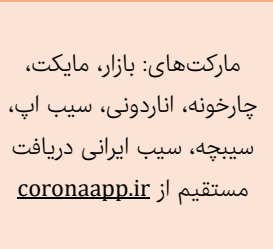 & 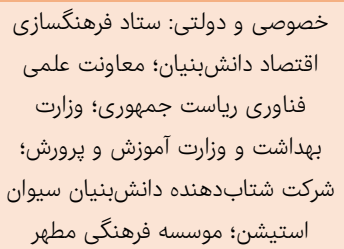 & $\checkmark$ & $x$ & سفيران سلامتى \\
\hline
\end{tabular}


1امه جr شيرين عبدالكريمى و همكاران

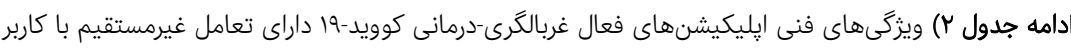

\begin{tabular}{|c|c|c|c|c|c|c|c|c|}
\hline نحوه ارايه بازخورد & امتياز كاربر & كعاد نظرات & تعداد نصب & نحوه دسترسى & 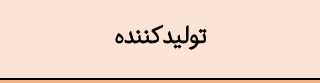 & مراكز درمانى & اشتراكگذارى & ايليكيشن \\
\hline تست سامانه برخط & $\mu / 7$ & $r \Lambda$ & 1000 & ماركت: بازار & خصوصى: شركت وادى رايمندان & $x$ & $x$ & دانستنىهاى كرونا (وادا) \\
\hline سامانه خودارزيابى & $\varepsilon / 0$ & 17 & 0.0 & ماركت: مايكت & خصوصى: بدون نام شركت/سازمان & $\checkmark$ & $x$ & كرونا \\
\hline سكامنه خودارزيابى & $\varepsilon$ & $\wedge$ & 0.0 & ماركت: بازار & خصوصى: بدون نام شركت/سازمان & $x$ & $x$ & تشخيص كرونا \\
\hline 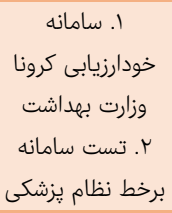 & r/Aq & 9 & 7000 & ماركت: مايكت & خصوصى: بدون نام شركت/سازمان & $x$ & $x$ & تست كرونا \\
\hline سكامانه خودارزيابى & - & - & 0.0 & ماركت: مايكت & 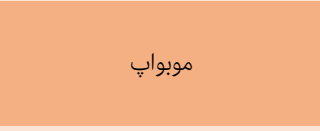 & $\checkmark$ & $\checkmark$ & كرونايلاس \\
\hline تست سامانه برخط & - & - & roo & ماركت: مايكت & ZeroOne & $\checkmark$ & $x$ & مقابله با كرونا \\
\hline
\end{tabular}

جدول س) توزيع انواع بازخورد در سامانهها، إيليكشنها و مشاوره برخط غربالكَرى-درمانى كوويد-19 (كرونا) داراى تعامل با كاربر

\begin{tabular}{|c|c|c|c|c|c|c|c|c|c|c|}
\hline ن بازخورد ارايه & ارجاع به & (قرنطينه، ايزالاسيون) & ر و درمان موارد مراقبت & نياز بيرى & يزياز ارجاع به & غربالكرى & بالينى & خطرزمينهاى عوامل & ارزيابى & إيليكيشن/سامانه \\
\hline اب/سامانه & $x$ & $x$ & $\checkmark$ & $x$ & $\checkmark$ & $\checkmark$ & & $\checkmark$ & $x$ & درمانكده \\
\hline اب/سامانه & $x$ & $\times$ & $x$ & $x$ & $\checkmark$ & $\checkmark$ & $\checkmark$ & $\checkmark$ & $\checkmark$ & ماسك \\
\hline اب/سامانه & $\checkmark$ & $\checkmark$ & $\checkmark$ & $\checkmark$ & $\checkmark$ & $\checkmark$ & $\checkmark$ & $\checkmark$ & $\checkmark$ & كرونا-110 \\
\hline إ/سامانه & $x$ & $x$ & $x$ & $\checkmark$ & $\checkmark$ & $\checkmark$ & $\checkmark$ & $\checkmark$ & $\checkmark$ & مقابله با كرونا \\
\hline سامانه & $x$ & $x$ & $x$ & $x$ & $\checkmark$ & $\checkmark$ & $\checkmark$ & $\checkmark$ & $x$ & خودارزيابى كرونا \\
\hline 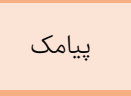 & $x$ & $x$ & $x$ & $x$ & $\checkmark$ & $\checkmark$ & $\checkmark$ & $\checkmark$ & $x$ & خودارزيابى كرونا- \\
\hline سامانه & $x$ & $x$ & $x$ & $x$ & $\checkmark$ & $\checkmark$ & $\checkmark$ & $\checkmark$ & $\checkmark$ & تست آنلاين كرونا \\
\hline سامانه & $x$ & $x$ & $x$ & $\times$ & $\checkmark$ & $\checkmark$ & $\checkmark$ & $\checkmark$ & $\times$ & خودارزيابى كرونا- \\
\hline تلفن/شفاهى & - & $\checkmark$ & $\checkmark$ & $\checkmark$ & $\checkmark$ & $\checkmark$ & $\checkmark$ & $\checkmark$ & $\checkmark$ & E०स。 \\
\hline تلفن/شفاهى & - & $\checkmark$ & $\checkmark$ & $\times$ & $\checkmark$ & $\checkmark$ & $\checkmark$ & $\checkmark$ & $\checkmark$ & 19. \\
\hline
\end{tabular}

جدول F امتيازدهى به إِليكيشنهاى فعال سلامتمحور كوويد-19 بر اساس مقياس

\begin{tabular}{|c|c|c|c|c|c|c|}
\hline نمره كلى & برداشت فرد از كيفيت برنامه & اطلاعات & زيباشناختى & عملكرد نرمافزار & تعامل & نام ايليكيشن فعال" \\
\hline$\mu / 7$ & $\mu / \varepsilon$ & $\varepsilon / 1$ & $\mu / \mu$ & $\mu / V$ & $\mu / \varepsilon$ & $\varepsilon_{0} \mu_{0}$ \\
\hline$\mu / 0$ & $\mu / l$ & $\mu$ & $\mu / V$ & $\varepsilon / r$ & $\mu / \mu$ & درمانكده \\
\hline$\mu / \mu$ & $r / 7$ & $\mu / 1$ & $\mathrm{~m} / \mathrm{O}$ & $\mu / q$ & $\mu / \mu$ & ماسك \\
\hline$\mu / l$ & $r / \mu$ & $\varepsilon / \psi$ & $\mu \%$ & $\mu / 7$ & $r / \mu$ & كرونا-110 \\
\hline$r / V$ & $1 / 0$ & $\mu / \varepsilon$ & $\mu / \mu$ & $\mu$ & $r / \mu$ & مقابله با كرونا \\
\hline$r / 7$ & 1/9 & $\mu / 。$ & $r / 0$ & $\mu / r$ & $r / \varepsilon$ & سفيران سلامتى \\
\hline$r / T$ & $1 / \varepsilon$ & $\mu / \Lambda$ & $r / \mu$ & $r / \mu$ & $1 / V$ & اخبار و تست كرونا \\
\hline$r / \Lambda$ & $1 / \pi$ & $r / 0$ & $r / 9$ & $r / \mu$ & $1 / V$ & مقابله با كرونا (zero one) \\
\hline$r / \circ$ & $1 / 1$ & $r / 9$ & $1 / 9$ & $r / r$ & $1 / V$ & تشخيص كرونا \\
\hline 1/9 & $1 / 1$ & $\mu / \Lambda$ & $1 / V$ & $r / r$ & $1 / 7$ & تست كرونا \\
\hline $1 / 9$ & $1 / \pi$ & $r / 7$ & $1 / \Lambda$ & r & $1 / 7$ & $\begin{array}{c}\text { آمار، تست و دانستنىهاىكرونا } \\
\text { (وادا) }\end{array}$ \\
\hline$r / 7$ & $r / \circ$ & $\mu / \mu$ & $r / \mathrm{V}$ & $\mu / 。$ & $r / \mu$ & ميانكين كل \\
\hline
\end{tabular}


بهطور فزايندهاى دست به دست هم دادهاند و از فناورى ارايهشده

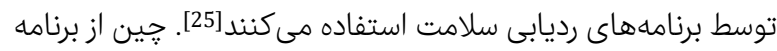

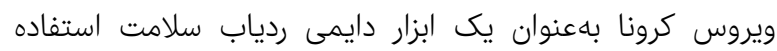

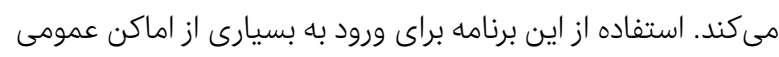

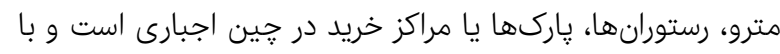

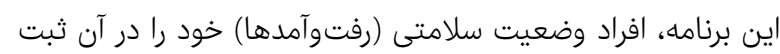

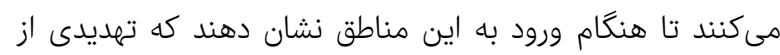

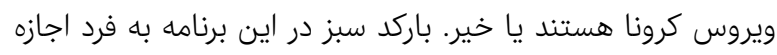

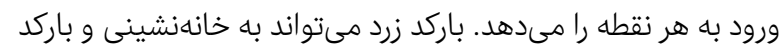

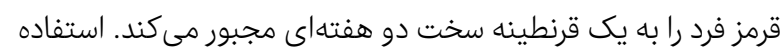

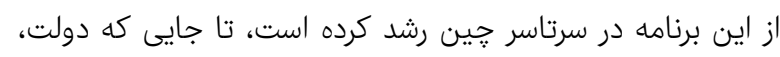

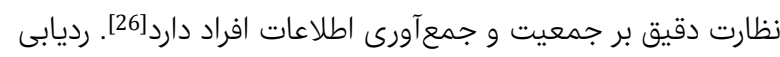

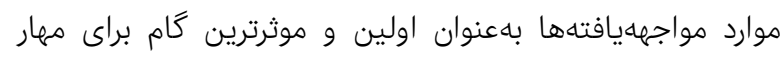

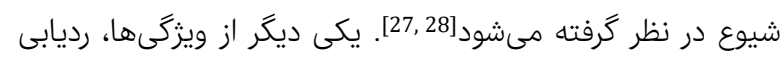

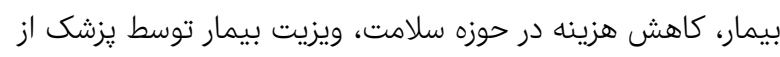

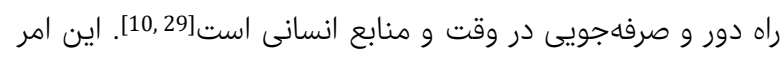

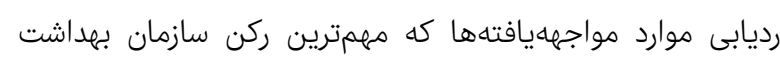

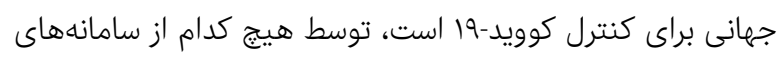
مورد بررسى ايرانى در داخل كشور انجام نمى كوديد.

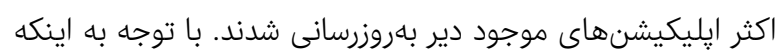

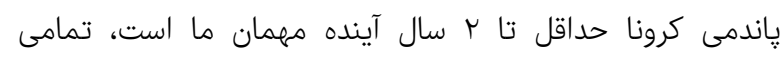

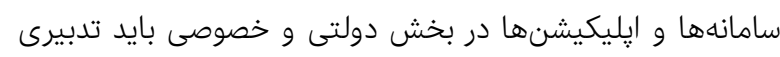

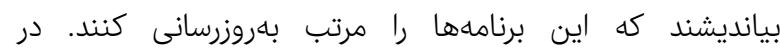

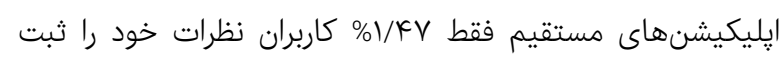

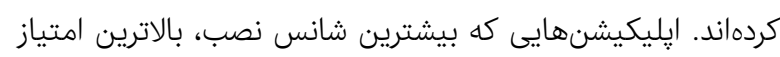

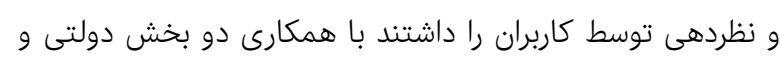

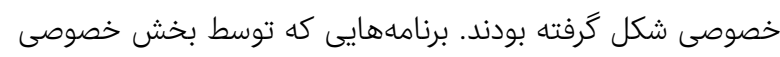

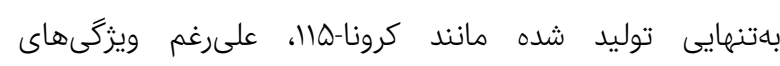

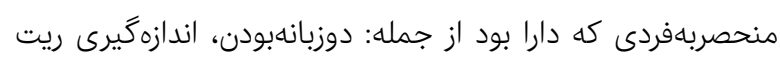

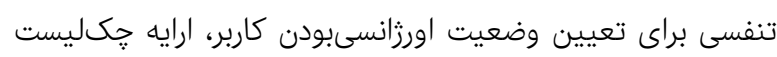

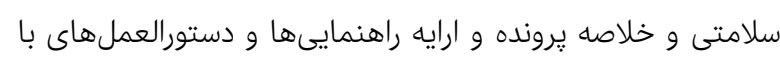

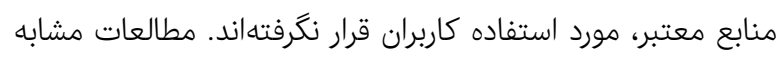

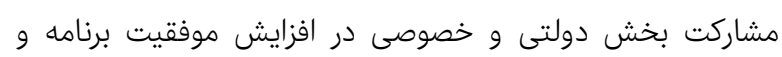

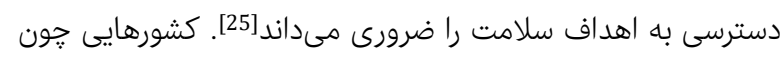

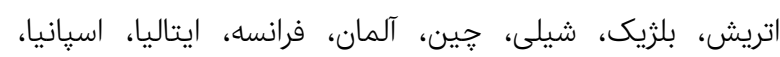

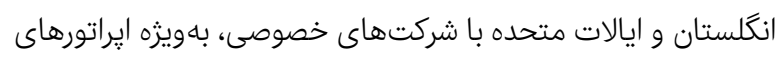

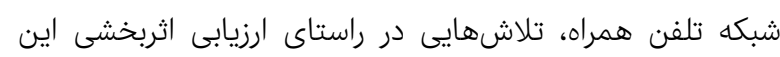

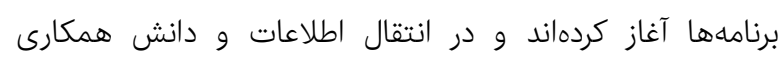
مى كنند [30].

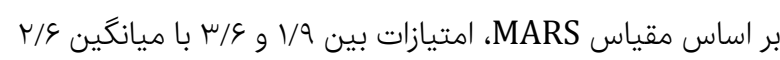

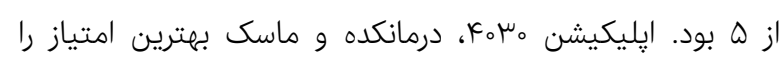

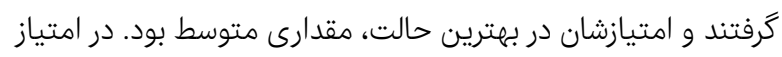

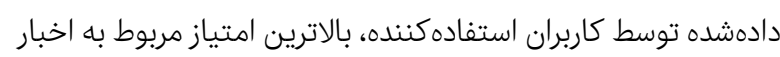

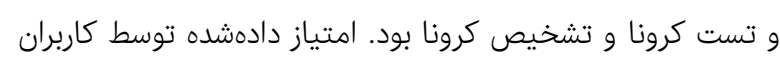

\section{بحث}

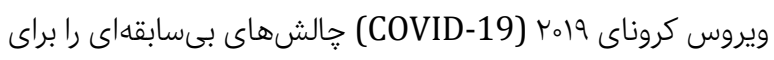

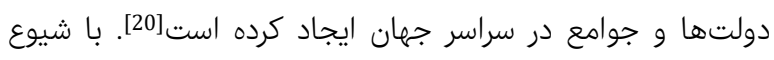

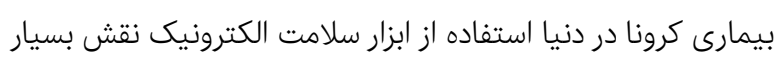

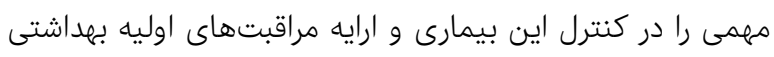

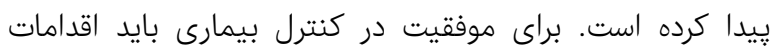

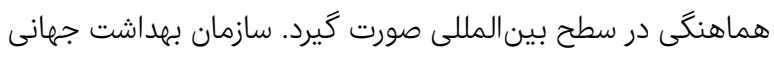

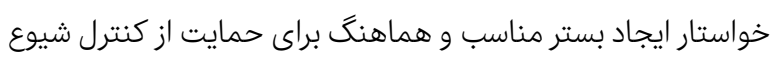

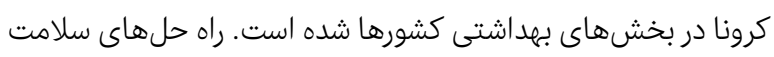

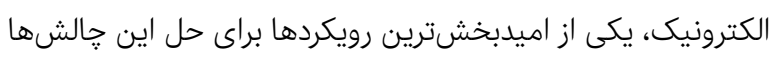

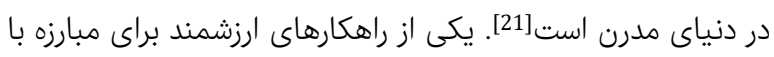

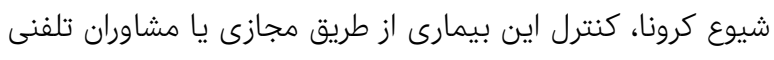

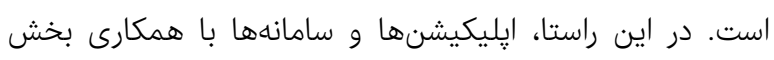

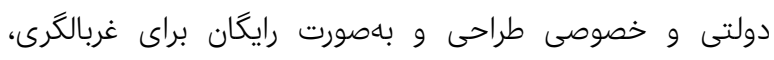

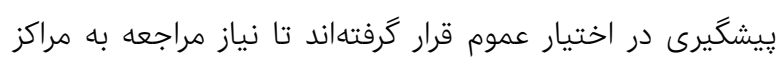

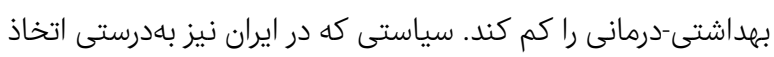

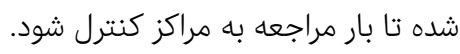

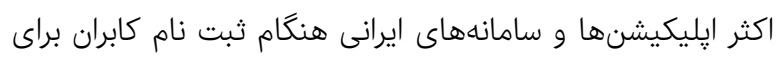

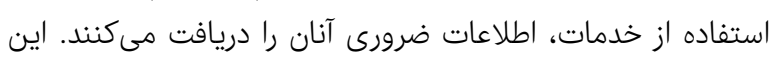

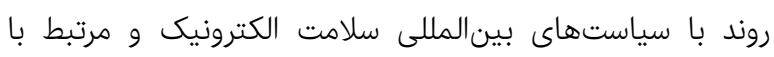

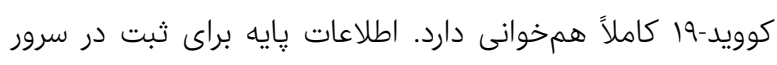

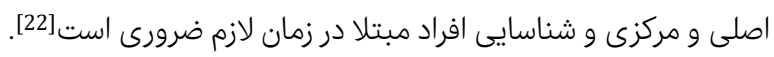

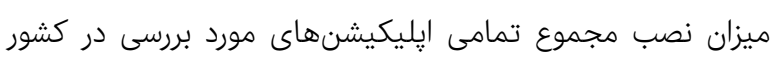

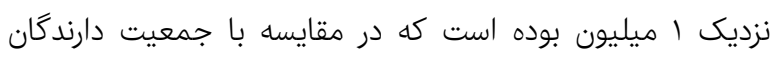

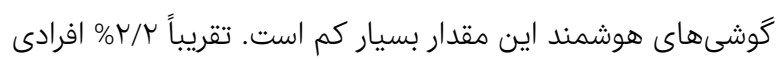

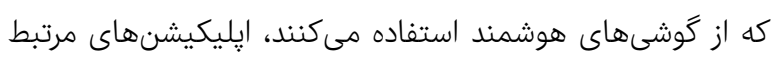

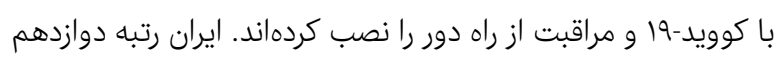

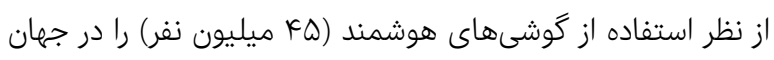

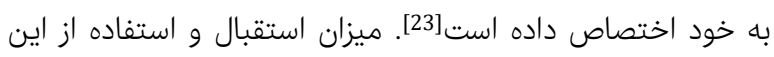

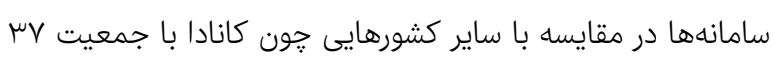

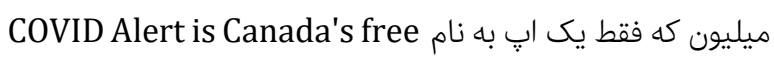

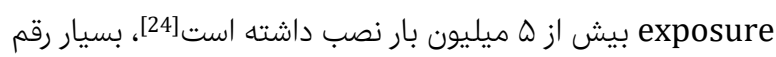

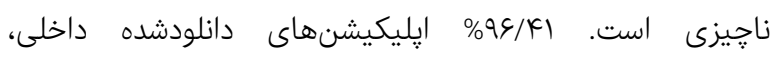

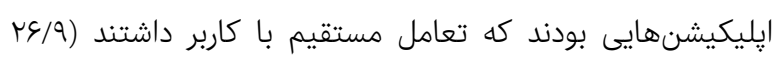

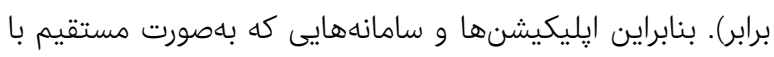

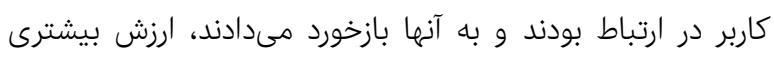

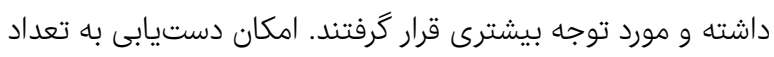

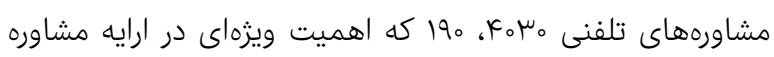

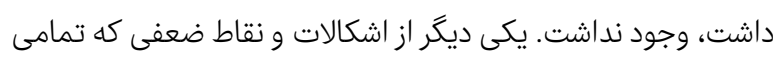

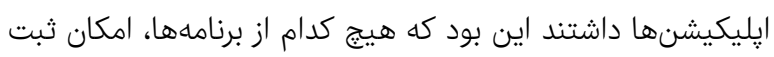

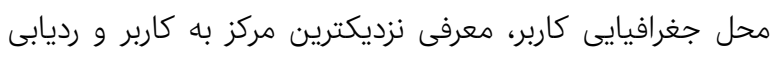
موارد مواجهايافته روى نقشه را ندارئ معرفي تزاشتندرين

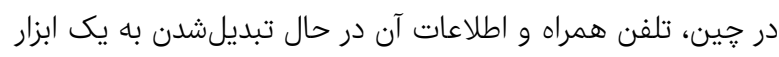

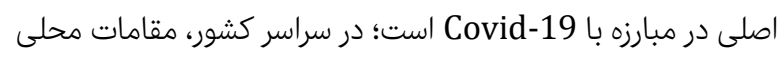


حركت به سمت سلامت الكترونيك، جالشهاى ويزه خود را دارد.

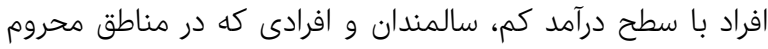

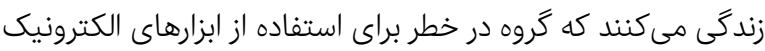

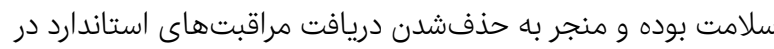

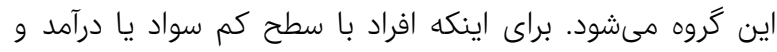

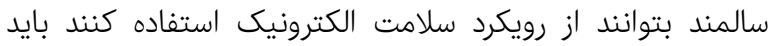

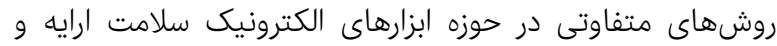

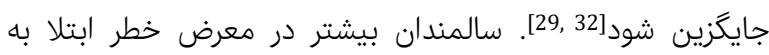

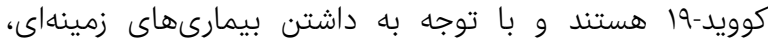

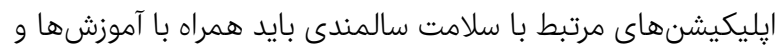

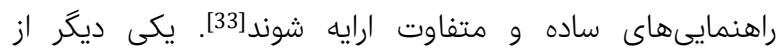
جالشهاى ابزارهاى سلامت الكترونيك، انتشار اطلاعات ناقص وراني

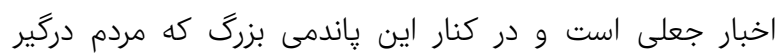

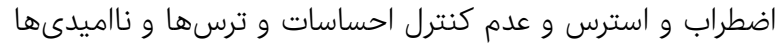

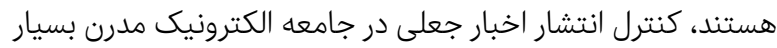

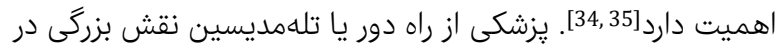

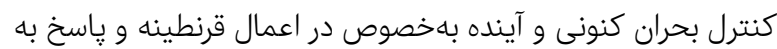

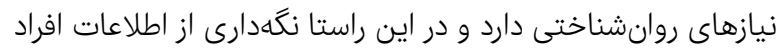

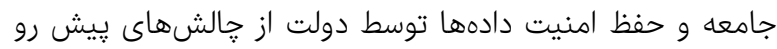

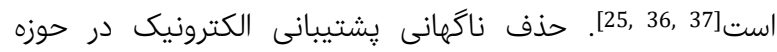

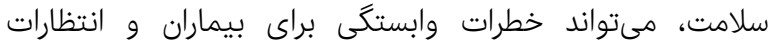
نامشخص را نيز همراه داشته باشد [38].

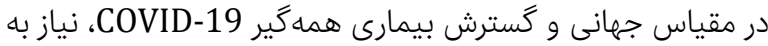

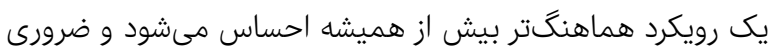

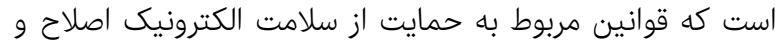

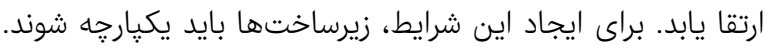

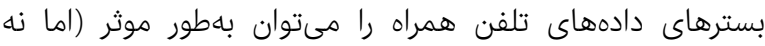

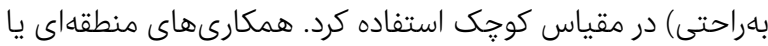

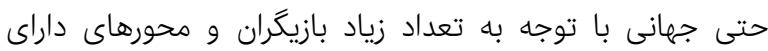

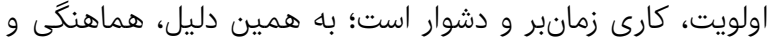

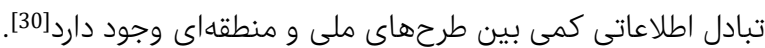

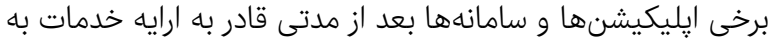

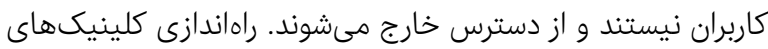

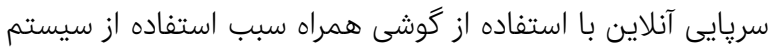

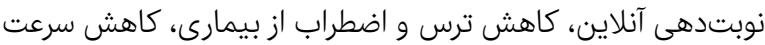

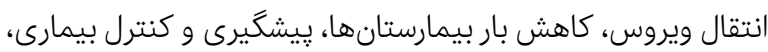

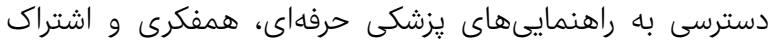

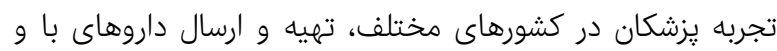

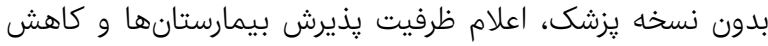

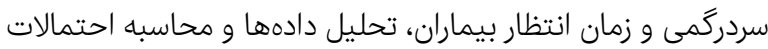

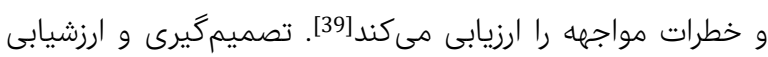

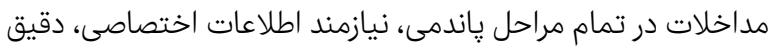

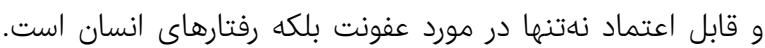
بحث بر اين است كه دادههاى تلفن همراه، هنكامى كه بهدرستى و
به اين ايليكيشنها بيشتر از امتياز كسبشده از MARS بود.

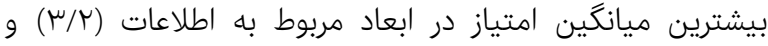

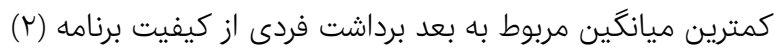

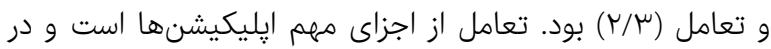

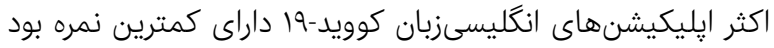

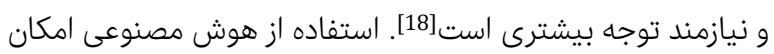

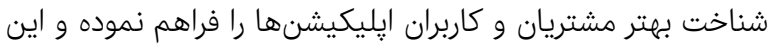
خردهمقياس را مىتواند ارتقا دهد.

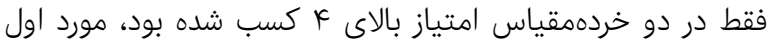

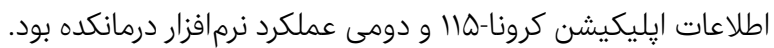
إيليكيشن درمانكده، قبل از شيوع كرونا توسط كاربران بران إناى مشاورها

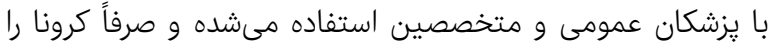

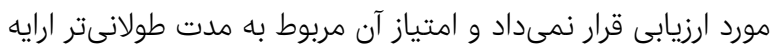

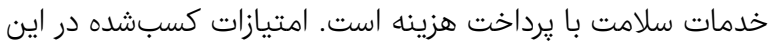
إيليكيشنها با استفاده از MARS در مقايسه با بإيليكيشن مشابه

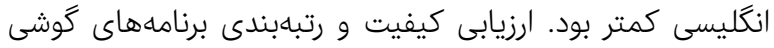

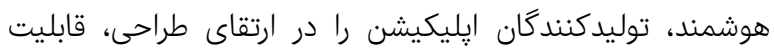

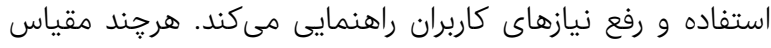

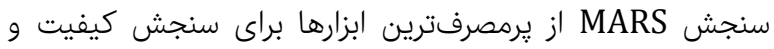
محتواى إيليكيشنها در حيطه سلامت است، ولى اين اين ابزار امكان إنان

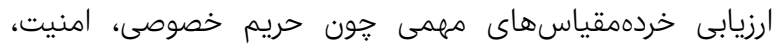

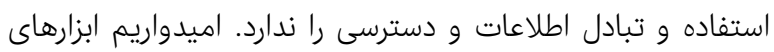
نوين ارزيابى كيفيت امكان سنجش اين خردهمقياسهاى ديدهنشاديه

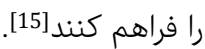

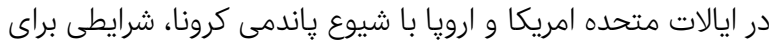

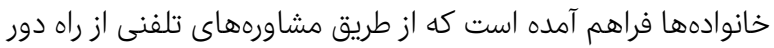

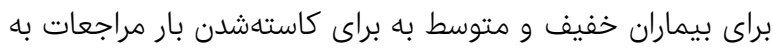

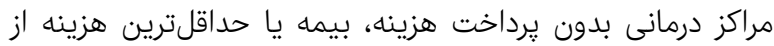

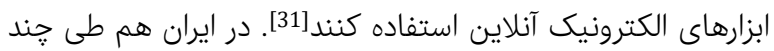

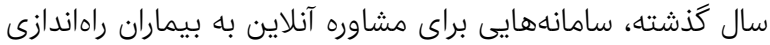

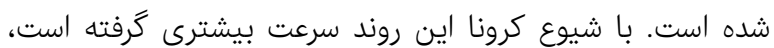

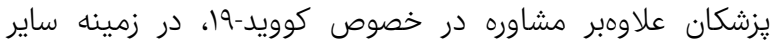

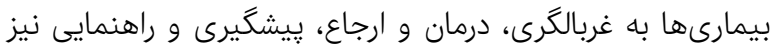

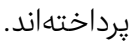
زيرساختهاى فناورى تلفن همراه بهمنظور دسترسى به مشاوره و

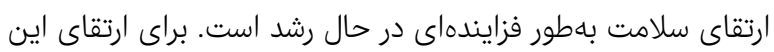

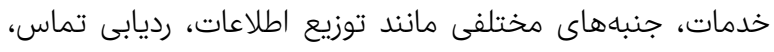

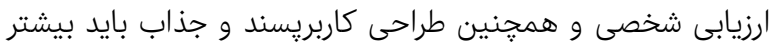

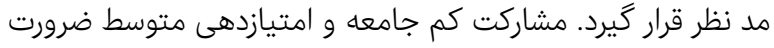

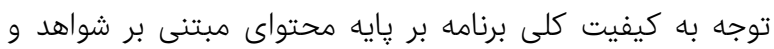

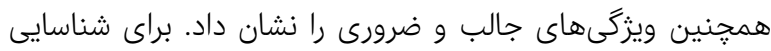

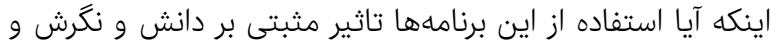

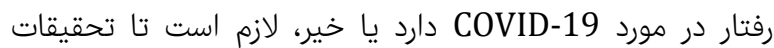

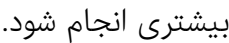




\section{نتيجه}

زيرساختهاى فناورى باهمنظور مشاوره و ارتقاى سلامت بهاطور فزايندهاى در حال رشد است. امكان دسترسى به مشاورههاى رايكان

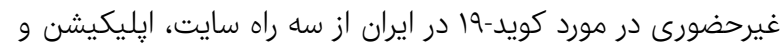

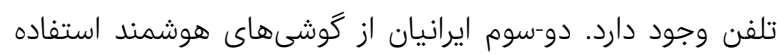

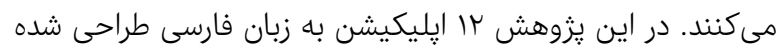

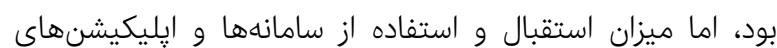

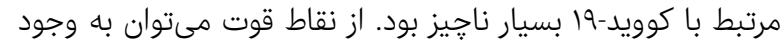

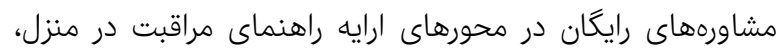

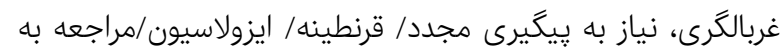

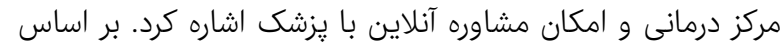

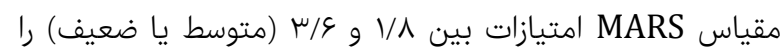
كسب كردند كه در مقايسه با إيليكيشن مشابه انكليسىزبان مانيان كمتر

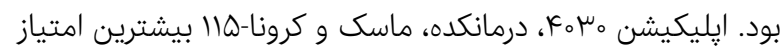

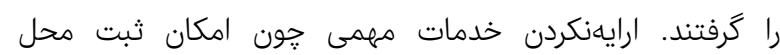
جغرافيايى كاربر، معرفى نزديكترين مراكز و رديابى موارد مواجهاته

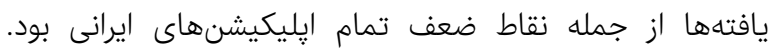

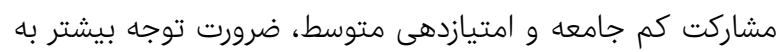

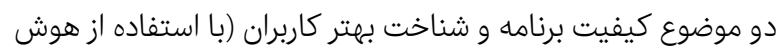
مصنوعى) براى استفاده بيشتر مخاطبان را خاطرنشان كرد.

تشكر و قدردانى: نويسندكان مراتب تشكر و قدردانى خود را از كمك

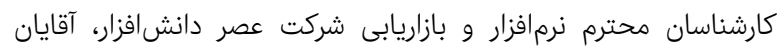

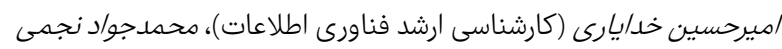

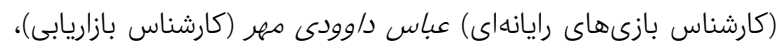

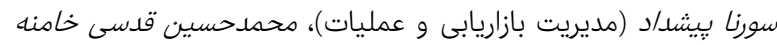

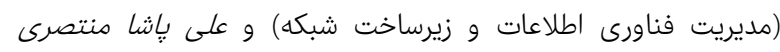

(دانشجوى مهندسى كامييوتر دانشعاه صنعتى شريف) اعلام مى إدارند.

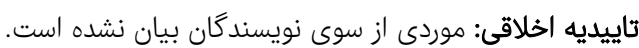

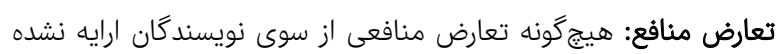

سهم نويسندكان: شيرين عبدالكريمى (نويسنده اول)، نكارنده

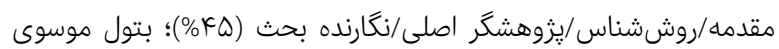

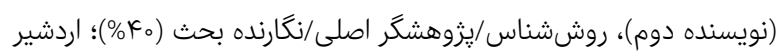

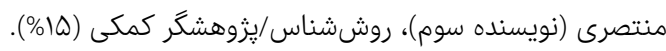

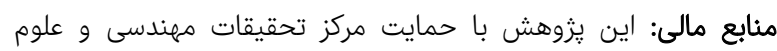
يزشكى جانبازان، تهران، ايران طراحى و اجرا شده است.

منابع

1- Zhao S, Musa SS, Lin Q, Ran J, Yang G, Wang W, et al. Estimating the unreported number of novel Coronavirus (2019-ncov) cases in China in the first half of January 2020: A data-driven modelling analysis of the early outbreak. J Clin Med. 2020;9(2):388.
با دقت استفاده مىشوند، بهترين ابزار پشتيبانى در اتخاذ

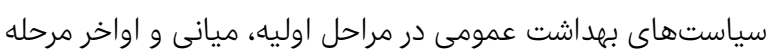
همه گير COVID-19 است [30]. راه حلهاى سلامت الكترونيك، يكى از اميدبخشترين رويكردها

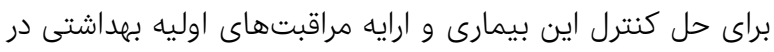

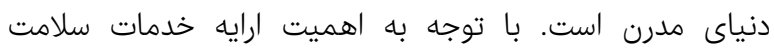
الكترونيك در كاهش بحران كرونا، استفاده از كوشى هوشمند در إنى حيطه سلامت ضرورى بهنظر مىرسد. وجود زيرساختهاى يكيارجنه براى مقابله با بحرانهاى ملى سلامت از اهميت ويزهاى برخوردار

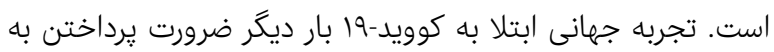

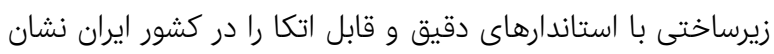

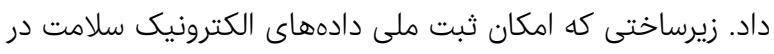

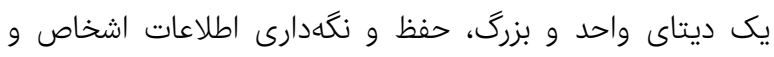
امنيت دادهها و قدرت انعطافيذيرى براى ارتقاى زيرساخت راء داش داشته

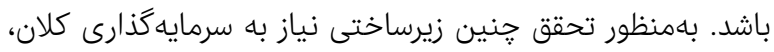

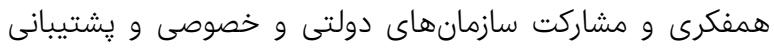

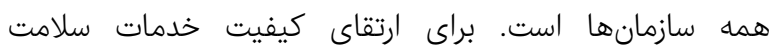

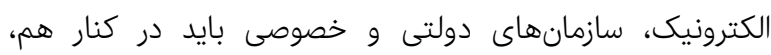

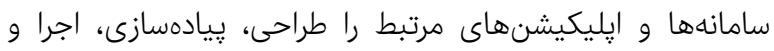

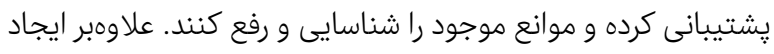

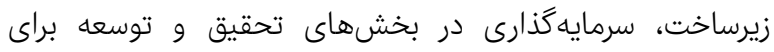

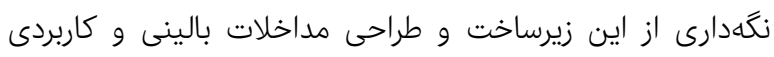

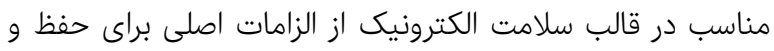

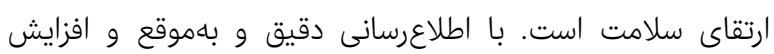

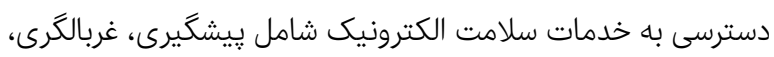
تشخيص، درمان و مراقبت به تمامى افراد جامعه مىتوانيم سطح سلامتى را افزايش دهيم.

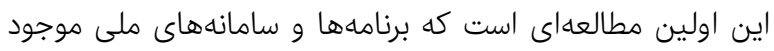

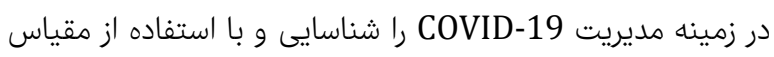

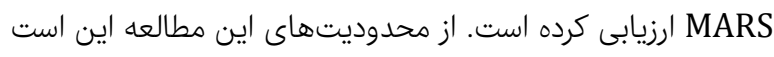

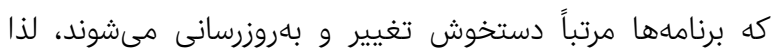

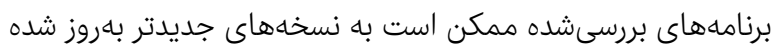

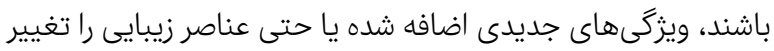

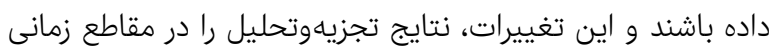
مختلف تغيير مىدهد. بهعلاوه، ممكن است كه برنامههايى وجود

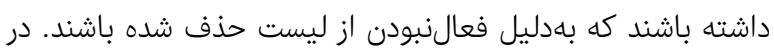

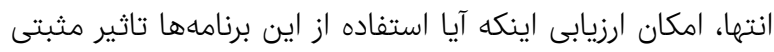

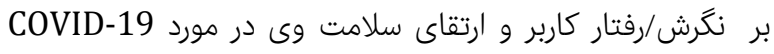

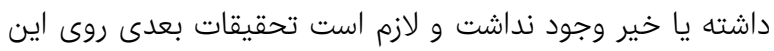

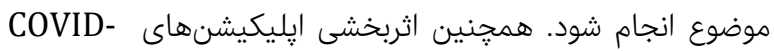

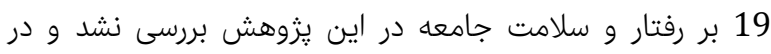
يزوهشهاى بعدى لازم است كه مورد توجه قرار گيرد. 
smartphone-based application to manage the treatment of people with heart failur. Iran J War Public Health. 2019;11(44):125-31. [Persian]

20- Anderson RM, Heesterbeek H, Klinkenberg D, Hollingsworth TD. How will country-based mitigation measures influence the course of the COVID-19 epidemic?. Lancet. 2020;395(10228):931-4.

21- World health organization. Responding to community spread of COVID-19: Interim guidance, 7 March 2020 [Internet]. Geneva: World Health Organization; 2020 [Cited 2020 October 18]. Available from: https://apps.who.int/iris/handle/10665/331421.

22- Abeler J, Backer M, Buermeyer U, Zillessen H. COVID19 contact tracing and data protection can go together. JMIR Mhealth Uhealth. 2020;8(4):19359.

23- Bankmycell [Internet]. New York: Bankmycell; 2020 [Cited 2020 October 18]. Available from: https://www.bankmycell.com/blog/how-many-phonesare-in-the-world.

24- Canada.ca [Internet]. Publisher City Unknown: Canada.ca; 2020 [Cited 2020 October 18]. Available from: https://www.canada.ca/en/public-

health/services/diseases/coronavirus-disease-covid19/covid-alert.html.

25- Zhou X, Snoswell CL, Harding LE, Bambling $M$, Edirippulige $S$, Bai $X$, et al. The role of telehealth in reducing the mental health burden from COVID-19. Telemed Health. 2020;26(4):377-9.

26- Mozur P, Zhong R, Krolik A. In coronavirus fight, China gives citizens a color code, with red flags [Internet]. New York: The New York Times; 2020 [Cited 2020 October 18]. Available from: https://www.nytimes.com/2020/03 /01/business/china-coronavirus-surveillance.html

27- Bashir Dar A, Hamid Lone A, Zahoor S, Amin Khan A, Naaz R. Applicability of mobile contact tracing in fighting pandemic (COVID-19): Issues, challenges and solutions. Comput Sci Rev. 2020;38:100307.

28- Collado-Borrell R, Escudero-Vilaplana V, VillanuevaBueno C, Herranz-Alonso A, Sanjurjo-Saez M. Features and functionalities of smartphone apps related to COVID19: Systematic search in app stores and content analysis. J Med Internet Res. 2020;22(8):20334.

29- Lopez Segui F, Franch Parella J, Girones Garcia X, Mendioroz Pena J, Garcia Cuyas F, Adroher Mas C, et al. A cost-minimization analysis of a medical record-based, store and forward and provider-to-provider telemedicine compared to usual care in Catalonia: More agile and efficient, especially for users. Int I Environ Res Public Health. 2020;17(6):2008.

30- Oliver N, Lepri B, Sterly H, Lambiotte R, Deletaille S, De Nadai M, et al. Mobile phone data for informing public health actions across the COVID-19 pandemic life cycle. Sci Adv. 2020;6(23):1-6.

31- Mahmood S, Hasan K, Colder Carras M, Labrique A. Global preparedness against COVID-19: We must leverage the power of digital health. JMIR Public Health Surveill. 2020;6(2):18980.

32- Nguyen A, Mosadeghi S, Almario CV. Persistent digital divide in access to and use of the internet as a resource for health information: Results from a California populationbased study. Int J Med Inform. 2017;103:49-54.

33- Banskota S, Healy M, Goldberg EM. 15 smartphone apps for older adults to use while in isolation during the COVID-19 pandemic. West J Emerg Med. 2020;21(3):51425.

34- Pennycook G, Mcphetres J, Zhang Y, Lu JG, Rand DG. Fighting COVID-19 misinformation on social media: 2- Wang M, Zhou Y, Zong Z, Liang Z, Cao Y, Tang H, et al. A precision medicine approach to managing 2019 novel Coronavirus pneumonia. Precis Clin Med. 2020;3(1):1421.

3- Cui J, Li F, Shi ZL. Origin and evolution of pathogenic Coronaviruses. Nat Rev Microbiol. 2019;17(3):181-92.

4- Danesh F, GhaviDel S. Coronavirus: Scientometrics of 50 years of global scientific productions. Iran J Med Microbiol. 2020;14(1):1-16. [Persian]

5- Nishiura H, Kobayashi T, Yang Y, Hayashi K, Miyama T, Kinoshita R, et al. The rate of underascertainment of novel Coronavirus (2019-nCoV) infection: Estimation using Japanese passengers data on evacuation flights. J Clin Med. 2020;9(2):419.

6- Bonilla-Aldana DK, Quintero-Rada K, MontoyaPosadaJP, Ramirez S, Paniz-Mondolfi A, Rabaan A, et al. SARS-CoV, MERS-CoV and now the 2019-novel CoV: Have we investigated enough about coronaviruses? a bibliometric analysis. Travel Med Infect Dis. 2020;33:101566.

7- Worldometers [Internet]. Publisher City Unknown: Worldometers; 2020 [Cited 2020 November 18]. Available from: https://www.worldometers.info/coronavirus/.

8- Liu J, Liao X, Qian S, Yuan J, Wang F, Liu Y, et al. Community transmission of severe acute respiratory syndrome Coronavirus 2, Shenzhen, China, 2020. Emerg Infect Dis. 2020;26(6):1320-3.

9- Huang C, Wang Y, Li X, Ren L, Zhao J, Hu Y, et al. Clinical features of patients infected with 2019 novel Coronavirus in Wuhan, China. Lancet. 2020;395:497-506.

10- Fagherazzi G, Goetzinger C, Rashid MA, Aguayo GA, Huiart L. Digital health strategies to fight COVID-19 worldwide: Challenges, recommendations, and a call for papers. J Med Internet Res. 2020;22(6):1-10.

11- Jalabneh R, Syed HZ, Pillai S, Apu EH, Hussein MR, Kabir R, et al. Use of mobile phone apps for contact tracing to control the COVID-19 pandemic: A literature review. SSRN Electron J. 2020;1-22.

12- Hosseini SM, Afkhami H. Content analysis of Iranian mobile healthcare applications for elderly. J New Media Stud. 2019;5(17):107-36. [Persian]

13- Chan AKM, Nickson CP, Rudolph JW, Lee A, Joynt GM. Social media for rapid knowledge dissemination: early experience from the COVID-19 pandemic. Anaesthesia. 2020;75(12):1579-82.

14- Parker MJ, Fraser C, Abeler-Dorner L, Bonsall D. Ethics of instantaneous contact tracing using mobile phone apps in the control of the COVID-19 pandemic. J Med Ethics. 2020;46(7):427-31.

15- Levine DM, Co Z, Newmark LP, Groisser AR, Jay Holmgren A, Haas JS, et al. Bates. design and testing of a mobile health application rating tool. NPJ Digit Med. 2020;3:74.

16- Whitehead L, Seaton P. The effectiveness of selfmanagement mobile phone and tablet apps in long-term condition management: A systematic review. J Med Internet Res. 2016;18(5):97.

17- Wicks P, Chiauzzi E. Trust but verify-five approaches to ensure safe medical apps. BMC Med. 2015;13:205.

18- Salehinejad S, Niakan Kalhori SR, Hajesmaeel Gohari S, Bahaadinbeigy K, Fatehi F. A review and content analysis of national apps for COVID 19 management using mobile application rating scale MARS. Inform Health Soc Care. 2021;46(1):42-55.

19- Davoudi Kongsofla M, Najafi Ghezeljeh T, Saeidi A, Peyravi H, Kiaroosta N. Design and evaluation of a 
تحليل محتواى سامانهها و آبهاى ايرانى سلامتمحور كوويد-19 س سبر

mental health and COVID-19: Using technology today to accelerate the curve on access and quality tomorrow. JMIR Ment Health. 2020;7(3):18848.

38- Inkster B, Obrien R, Selby E, Joshi S, Subramanian V, Kadaba M, et al. Digital health management during and beyond the COVID-19 pandemic: Opportunities, barriers, and recommendations. JMIR Ment Health. 2020;7(7):19246.

39- Shu M, Li J. Health digital technology in COVID-19 pandemic: Experience from China. BMJ Innov. 2020;6(4):259-61.
Experimental evidence for a scalable accuracy nudge intervention. Psychol Sci. 2020;31(7):770-80.

35- Ni MY, Yang L, Leung CMC, Li N, Yao XI, Wang Y, et al. Risk factors, and social media use during the covid-19 epidemic and cordon sanitaire among the community and health professionals in Wuhan, China: Cross-sectional survey. JMIR Ment Health. 2020;7(5):19009.

36- Liu S, Yang L, Zhang C, Xiang YT, Liu Z, Hu S, et al. Online mental health services in China during the COVID19 outbreak. Lancet Psychiatry. 2020;7(4):17-8.

37- Torous J, Myrick JK, Rauseo-Ricupero N, Firth J. Digital 